\title{
Teachers Education: a Project for Evaluation/Self Assessment in Educational and Lifelong Learning Way. A first Report of Research Experience
}

\author{
Gabriella Aleandri*, Luca Girotti** \\ * Associate Professor of General and Social Pedagogy at Dept. of Education, Cultural Heritage and \\ Tourism, \\ University of Macerata, Italy \\ ** Assistant Professor of Experimental Pedagogy at Dept. of Education, Cultural Heritage and \\ Tourism, \\ University of Macerata, Italy
}

\begin{abstract}
The paper aims at stressing the discussion about the significant and topical issues that are evaluation and self-assessment in educational contexts, from teachers' initial tertiary education and training to in-service and lifelong one. Finally, we will point out the strategic functions derived from building an organic evaluation system, which may allow a systemic and overall look about the whole scope of evaluation, as well as promote and improve a monitoring network. It will be useful primarily for teachers to know about their professional activities and have thus the opportunity to improve. Moreover, we will illustrate some results of a first experience on the investigation into the knowledge and ideas of the students attending the Primary Education degree course at the University of Macerata (Italy). Such survey is included within a broader research project about outcomes of future teachers. The methodologies used are both quantitative (most used statistical methods) and qualitative (a method autonomously adapted from Grounded Theory by Glaser and Strauss). A first data analysis shows that, as written by the students of the pilot sample, the characteristic that must not fail the teacher to be a good evaluator is objectivity, an aspect also much discussed within the scientific community.
\end{abstract}

Keywords: Teacher Education, Pedagogical research, Evaluation and Assessment, Lifelong Education.

\section{Introduction}

Nowadays, the pedagogical issue about evaluation matter has become a priority both in everyday school and university life and as discussing among scholars and in the most recent educational policies. That topic became ever more significant both at international and national level.

Therefore, in Italy, a series of legislative measures have been taken, that have resulted, among other things, in establishment of INVALSI institution (which replaced the past CEDE assessment institution) as well as the "younger" ANVUR and AVA. All those allow us to highlight the growing awareness at all levels that the evaluation is a strategic lever to revive and upgrade the education and training system, both within university degree programs and in in-service and lifelong learning way. In fact, it has come to have, on the one hand, a considerable literature - pedagogical one too - on the subject and, on the other hand, a significant wealth of experience in/of schools.

However, in this debate the risk both of the absence of an adequate systemic overall design and of the "actual" marginality of the teachers' professional, with the deempowerment of those involved, is still actual.

The plurality of times and school assessment tools are likely to be devoid of meaning and direction, without a vision system and a non-adequate initial nor in-service teachers education and training (in a perspective of lifelong learning and education). 
Instead, although that difficult context, the years of teachers university education and training can be an important resource in theoretical (docimological education) and practice (internship experience) terms, especially in a strategic pedagogical perspective to promote a culture of evaluation and self-assessment.

It is therefore relevant and meaningful, within pedagogical reflection and educational research, reflecting about the idea that the future teachers have about the aims of school evaluation and about the characteristics that the teacher must have to be a good evaluator. Furthermore, we will propose evaluation tests and self-assessment about their curricular knowledge to such students, in view of the Dublin descriptors too that make up the references in preparing the educational objectives of university courses, as well as bearing in mind the subject areas of the curriculum of school cycles at which they will teach.

\section{Methods and results}

The research project consists in several steps in which they were used, and will be used, both quantitative methodology choosing the most common statistical methods in education and social sciences and qualitative methodology, by autonomously planning and modifying in a more flexible and adaptable way the Grounded Theory primarily conceived by Glaser and Strauss.

In this report about initial phase, we highlighted positive aspects, deficient or to be implemented or improved through a careful pedagogical reflection that will result in proposals for revision/integration of both the initial university curriculum and in the perspective of lifelong education.

The several moments and school assessment tools are likely to be devoid of meaning and direction, with no:

- An overview of the system and

- An inadequate initial and in-service (in a perspective of lifelong learning and education) of teachers.

The idea underlying the research project lies in the reflection that comes from what argued above, that the years spent in teachers university education and training can be an important resource both in theoretical terms (docimological training) and practical (internship experience), especially in a strategic pedagogical perspective that aims to promote a culture of evaluation and self-assessment.

It is therefore relevant and significant, in terms of pedagogical reflection and educational research, making the object of reflection:

- The idea that future teachers have of the school evaluation and the characteristics that must have the teacher to be a good evaluator;

- The data obtained from tests of self-assessment and evaluation of the course curriculum by future teachers. That is strategic also in view of the Dublin descriptors that constitute the references in preparing the educational objectives of the university courses, as well as keeping in mind the subject areas of the curricula of school cycles in which they will teach.

In this paper we will present some data related to a research phase that is part of a broader research project concerning the education and training of future kindergarten 
or primary teachers, both as regards the initial university education and as regards the more complex and still "nebulous" education and training in the perspective of lifelong and life-wide learning. They will be investigated and analyzed according to a framework as possible systemic and global.

The pilot-sample is made up by enrolled students attending third year of Primary Education Course degree at University of Macerata. It is a first pilot sample to test the instruments used for surveys.

Subsequently we will analyze all the results of those initial findings, we will do any changes of the tools used, and progressively enlarged the sample: first of all, to each Primary Education Course students enrolled at the University of Macerata, and then, further, to Primary Education Course students attending in many Italian universities.

That phase of the research is based on the use of a test made up of several areas for evaluation/self-assessment of knowledge and competences of the students, as we have already said, of Primary Education Sciences Courses at the University of Macerata, Italy.

The objectives of this first phase concerning the self-assessment / evaluation of the knowledge and skills of students in the following areas:

1) assessment: by identification of essential features in the opinion of the students (pre-survey phase)

2) general and transversal skills (in the same perspective with the project TECO and with the objectives set by the Dublin descriptors)

3) knowledge and skills in main basic contents, analytical reasoning, problem solving and written communication, as well as critical analysis, relating to the curricular competences taken from the pedagogical disciplines and the other planned for the first year of studies in Primary Education Course

4) knowledge and skills extrapolated from the National Guidelines for Curriculum of Primary School in 2012, prepared by the Italian Ministry of Education, University and Research.

About instruments and procedures, the first stage they consists in freely writing and then discussing in the classroom; the second stage in administration of three composites test (understanding and critical analysis, writing, multiple choice answers); third stage in self-assessment by the students themselves according to the criteria given in rehearsal; and last fourth stage in evaluation by the research team.

The main purposes of such four stage are to:

- Measure the ability of self-assessment,

- Detect the level of skills,

- Identify matching curriculum offer of the Primary Education Course or a shortcoming compared to the required skills and outcomes.

Thereafter, taking into account the data obtained we will perform and share careful pedagogical reflections that will result in proposals for revision / integration / improvement of both the initial university curriculum and in-service and lifelong education and training.

About the first report of survey on the identification of the characteristics of the evaluation, in particular regarding the conduct of the test, we specify that during 
exercise in the classroom there were 31 students, including 1 Spanish (Erasmus), who was not taken into account in this survey.

So thirty were the tests were considered valid.

The gender composition of the class is a clear predominance of women, as shown in the pie chart below (Chart 1 ).

\section{Chart 1.}

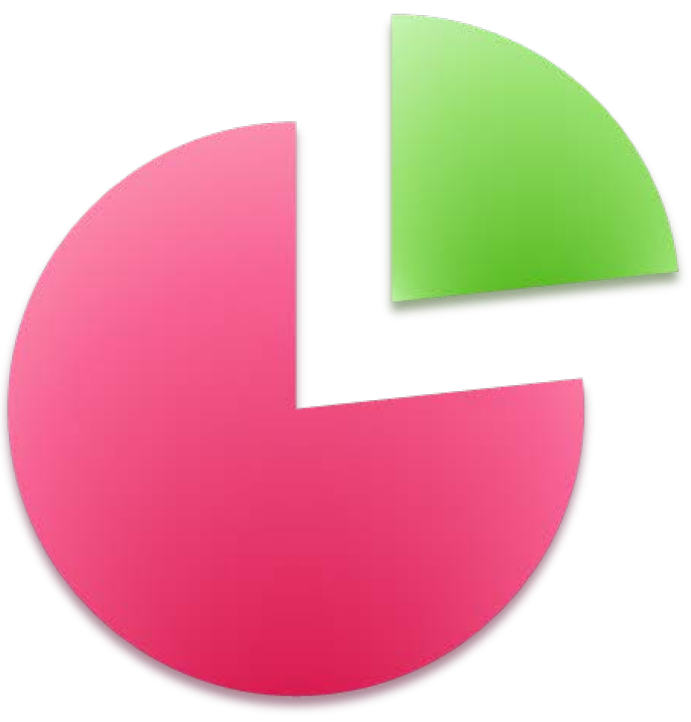

MASCHI

- FEMMINE

The age of participants was rather uniform: about $2 / 3$ of the students is 20 years old, and just under one third is 21 years old, and only three have different ages (Chart 2).

\section{Chart 2.}

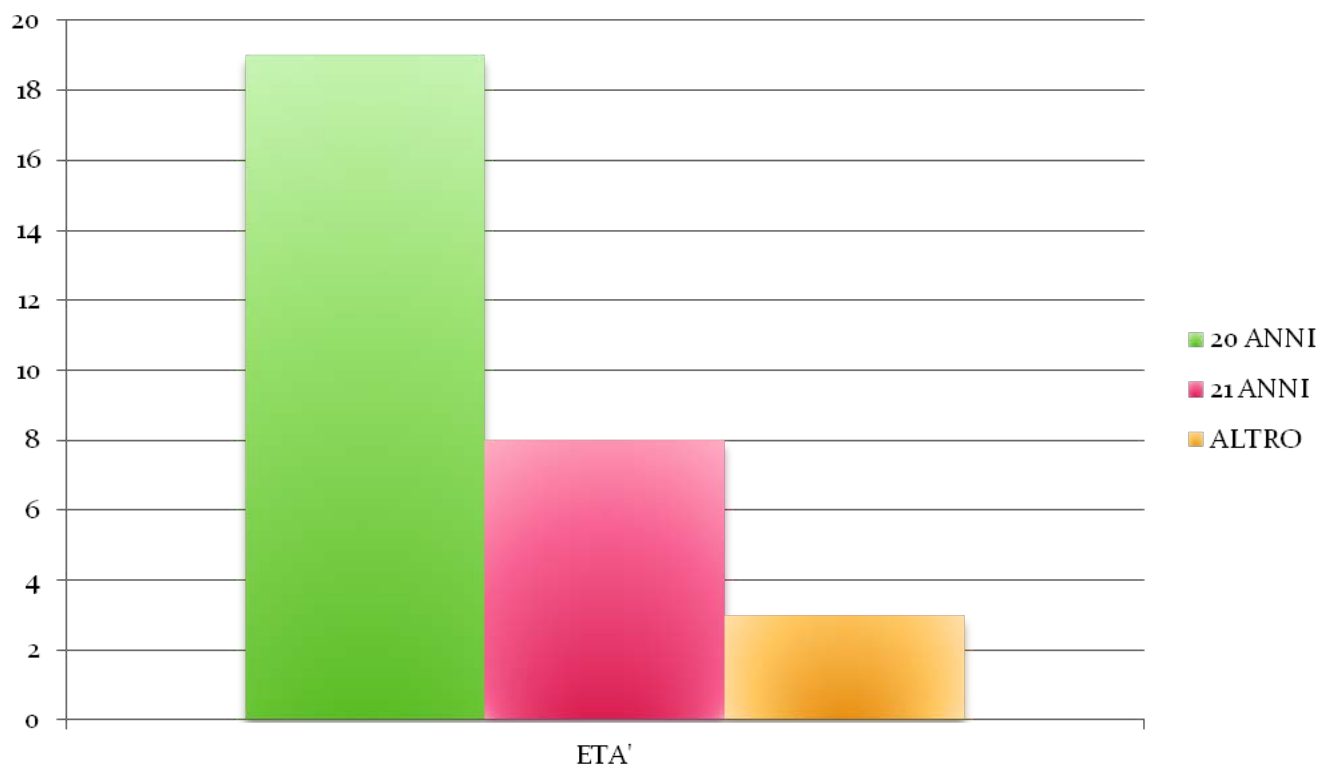

Regarding the year of course it is been also highlighted the correlation between years of student enrolment and years of placement of the course in the curriculum and age of students placed between 20 and 21 years (Chart 3). 


\section{Chart 3.}

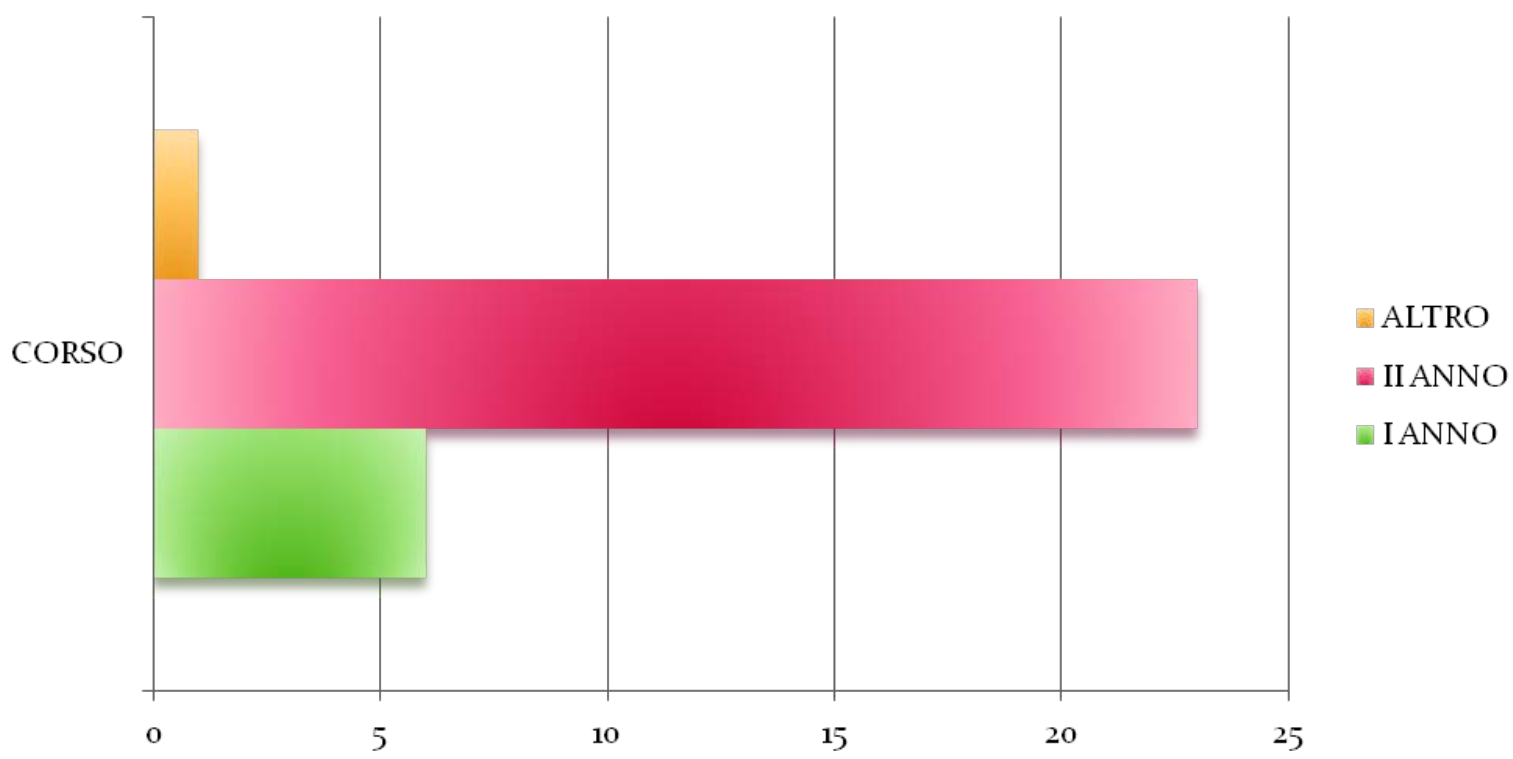

The main question / stimulus was: "What feature should not be lacking to the teacher to be a good evaluator?” Students answered as following shown in Chart 4.

Chart 4.

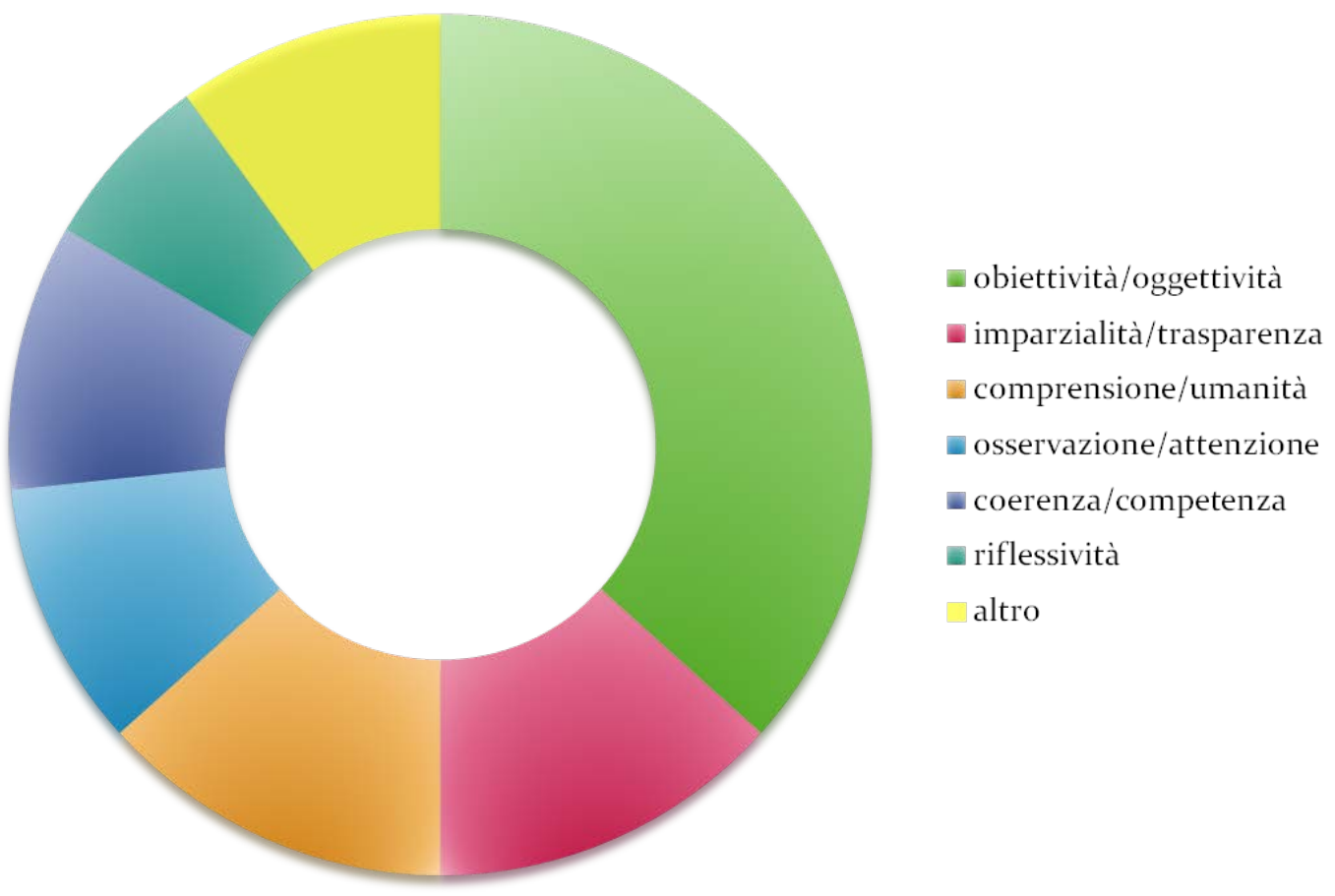


According as written by the students from the pilot sample, the characteristic that must not fail the teacher to be a good evaluator, which is clear, is that objectivity to confirm that, even in the perception of future teachers, this appears the primary need.

To this are added other features in the same perspective, such as transparency and impartiality.

\section{Discussion and Conclusions}

This paper discusses the results of a first experience of survey in the initial stages of a research and evaluation project in order to university education and training (in this step we refer to the initial one) of teachers of kindergarten and primary school, at the University of Macerata. Italy, which is part of a larger research project.

The above shown data are early, initial, and not representative, results. Nevertheless, they are still very interesting, as it seem they are going towards the opposite direction to what, however, has been clearly emphasized in the literature. We refer for example to the contributions by G. Domenici (2010) and M. Castoldi (1995), that is the critical approaches to this issue, in which it is highlighted that the objectivity on the one hand lies in the test, on the other hand that this is a "myth" of the traditional theories and point of view on evaluation.

Initial prospects of reflection: of course, we point out again this is only a first, episodic, survey that needs further study before we can proceed by offering significant reflections, but probably it is not entirely misplaced to hypothesize that the proximity to their experience as students at higher secondary schools - in which the perception is not the objectivity of the evaluation suffered - can constitute an experiential reference which may have weighed in answering to the question.

Note, finally, the appearance (albeit reduced), in the opinion of the students, of all those features that recall the idea of a caring teacher of the student, able "to read" the situation and be able to refer to evaluation also his evaluating. We think that it is important reflecting starting from these initial findings about evaluation towards meanings near to "take care, analyse in depth", to be aware and responsible, in teaching professions, and, on the opposite site, far from evaluation resulting in punishment or ranking.

After the above presented first phase, subsequent assessment tests / self-evaluation are currently carrying out. We're going to test general and transversal knowledge and skills related to: a) TECO test by Italian Conference of Rectors, b) progress test and c) knowledge and skills extrapolated from the National Guidelines for Curriculum of Primary School in 2012, prepared by the Italian Ministry of Education, University and Research (see above), of which we will be able to report the results in further research papers.

\section{References}

Aleandri, G. (2003). I sistemi formativi nella prospettiva dell'economia globale. Per una pedagogia del lifelong learning. Roma: Armando.

Aleandri, G. (2011). L'educazione permanente nella prospettiva del lifelong e lifewide learning. Roma: Armando. 
Aleandri, G., \& Girotti, L. (2010). Educational research and Policy-making. Questions, Challenges and Perspectives for a pedagogical debate. Education Sciences \& Society, (2), 64-117.

Aleandri G., \& Girott,i L. (2011). Admission test to Primary Teacher Education: some empirical evidences and reflections from UNIMC experience. Education Sciences \& Society, (2),162-175.

Aleandri, G., \& Girotti, L. (2013), Lifelong learning and training: a never ending challenge and choice for educational system. Procedia - Social and Behavioral Science.

ANVUR (2014), Assessing the generic competences acquiring by students graduating form Italian universities. Rome: Anvur.

Castoldi, M. (1995). Verso una scuola che apprende. Strategie di autoanalisi d'istituto. Roma: SEAM.

Cavalli, A., \& Argentin, G. (a cura di), (2010). Gli insegnanti italiani: come cambia il modo di fare scuola. Terza indagine IARD sulle condizioni di vita e di lavoro nella scuola italiana. Bologna: Il Mulino.

CERI-OECD (2007). Evidence in Education. Linking research and policy. Paris: OECD.

CERI-OECD (2008). Innovating to learn, Learning to Innovate.Paris: OECD.

Cochran-Smith, M. [et al.] (eds.), (2008) Handbook of research on teacher education: enduring questions in changing contexts.New York: Routledge.

Day, C. (ed.) (2012). International handbook of theacher and school development. London: Routledge.

Delors, J. (1996), Learning: the Treasure within. Paris: UNESCO. Tr. It. Nell'educazione un tesoro. 2nd ed. Roma: Armando, 2000.

Domenici, G. (a cura di), (2010). La valutazione come risorsa. Napoli: Tecnodid.

EUROPEAN COMMISSION (1996). Teaching and Learning: towards the learning society (White Paper on Education and Training). Brussels: European Commission.

Furlong, J. [et al.] (eds.), (2009). Policy and politics in teacher education: international perspectives. New York: Routledge.

Girotti, L. (2009). La ricerca educativa per l'orientamento. Macerata: EUM.

OECD, (2007). Education at a Glance: OECD Indicators - 2007 Edition. Paris: OECD (EAG 2007), tr. it. Uno sguardo sull'educazione. Gli indicatori dell'OCSE 2007. Roma: Armando.

OECD, (2008). Education at a Glance: OECD Indicators - 2008 Edition. Paris: OECD (EAG 2008), tr. it. Uno sguardo sull'educazione. Gli indicatori dell'OCSE 2008. Roma: Armando, 2009.

OECD, (2009). Education at a Glance: OECD Indicators - 2009 Edition. Paris: OECD (EAG 2009), tr. it. Uno sguardo sull'educazione. Gli indicatori dell'OCSE 2009. Roma: Armando, 2010. 